\title{
Null Allele
}

National Cancer Institute ( $\mathrm{NCl})$

\section{Source}

National Cancer Institute (NCI). Null allele.

A mutation that results in either no gene product or the absence of function at the phenotypic level. 